\title{
PAPER
}

\section{Multidisciplinary rehabilitation for people with Parkinson's disease: a randomised controlled study}

\author{
D T Wade, H Gage, C Owen, P Trend, C Grossmith, J Kaye
}

J Neurol Neurosurg Psychiatry 2003;74:158-162

See Editorial Commentary p 148

See end of article for authors' affiliations

....................

Correspondence to: Professor Derick T Wade,

Oxford Centre for

Enablement, Windmill

Road, Oxford OX3 7LD,

UK:

derick.wade@dial.pipex.com

Received 29 May 2002

In revised form 30 August

2002

Accepted 12 September

2002 Objective: To determine whether a programme of multidisciplinary rehabilitation and group support
achieves sustained benefit for people with Parkinson's disease or their carers.

Methods: The study was a randomised controlled crossover trial comparing patients and carers who had received rehabilitation four months before assessment with those who had not. Patients were recruited from a neurology clinic, attended a day hospital from home weekly for six weeks using private car or hospital transport, and received group educational activities and individual rehabilitation from a multidisciplinary team. Patients were assessed at entry and at six months using a 25 item self assessment Parkinson's disease disability questionnaire, Euroqol-5d, SF-36, PDQ-39, hospital anxiety and depression scale, and timed stand-walk-sit test. Carers were assessed using the carer strain index and Euroqol-5d.

Results: 144 people with Parkinson's disease without severe cognitive losses and able to travel to hospital were registered (seven were duplicate registrations); 94 had assessments at baseline and six months. Repeated measures analysis of variance comparing patients at the 24 week crossover point showed that those receiving rehabilitation had a trend towards better stand-walk-sit score $(p=0.093)$ and worse general and mental health $(p=0.002, p=0.019)$. Carers of treated patients had a trend towards more strain $(p=0.086)$. Analysis comparing patients before and six months after treatment showed worsening in disability, quality of life, and carer strain.

Conclusions: Patients with Parkinson's disease decline significantly over six months, but a short spell of multidisciplinary rehabilitation may improve mobility. Follow up treatments may be needed to maintain any benefit.
$\mathrm{P}$ arkinson's disease is a common cause of disability, especially in the elderly. ${ }^{2}$ Drug treatment is remarkably effective in the early stages but in most patients the disease progresses so that they become increasingly disabled despite optimal drug therapy. ${ }^{3}$ Furthermore there is some reluctance to use drugs, both in the early stages and at doses that fully reverse the impairments, because it is possible that drugs themselves affect the progress or manifestations of the disease. ${ }^{3}$ Surgical treatments are also available ${ }^{4}$ but carry risks and anyway could not be used on the majority of patients. Consequently there is a role for non-pharmacological interventions, ${ }^{5-8}$ which should proceed in parallel with drug treatment, especially as it has been found that the main factors influencing quality of life are depression, disability, postural instability, and cognitive decline. ${ }^{9}$

There have been several systematic reviews investigating aspects of rehabilitation in patients with Parkinson's disease, but with one exception ${ }^{10}$ they conclude that there is no useful evidence to support or refute any specific or general rehabilitation intervention. ${ }^{11-13}$ However, recent research does suggest that multi-professional expert teams may offer effective and efficient rehabilitation to patients with complex neurological disability, whether acute ${ }^{14}$ or progressive. ${ }^{15}$ There is some evidence that a specialist day hospital setting is an effective way of delivering rehabilitation. ${ }^{16}$ Group occupational therapy has been found to be effective for Parkinson's disease in one trial. ${ }^{18}$

We therefore set up a study to investigate the effectiveness of a six week course of rehabilitation involving both individualised treatments offered by a multidisciplinary team and group educational support. The programme was delivered in a day hospital setting to patients living in the community. Analysis of data collected immediately after intervention was completed has suggested some immediate benefit, ${ }^{19}$ but the primary goal of this study was always to investigate the effects four months after the end of intervention.

\section{METHODS}

We used a randomised, single blind controlled crossover design comparing six weeks of active intervention with no active intervention, assessing the outcome at six months after entry. The actual design and flow of patients were influenced by two factors: all patients had to be offered treatment, both because the funding was primarily intended to deliver a service and because team members wanted this; and access to facilities was limited, such that only one group of six patients could be treated at any one time. Therefore the control group received the intervention six months after entry, immediately after their second assessment, and both groups were reassessed at one year.

Patients were recruited in cohorts of 12 , randomised into two groups of six with one receiving early and one delayed intervention. As shown in fig 1, one cycle included 48 patients and lasted 48 weeks. We aimed to recruit 144 patients in 12 cohorts, giving 24 separate treatment groups over three cycles in three years.

The main analysis was a comparison of outcomes at 24 weeks, when one group of patients had received the intervention-finishing about four months before-and the other group was about to start treatment. To control for any imbalance at entry, a repeated measures analysis of variance

Abbreviations: HAD, hospital anxiety and depression scale; NHPT, nine hole peg test; PDQ, Parkinson's disease questionnaire; SF-36, short form 36 item health survey; UPDRS, unified Parkinson's disease rating scale 


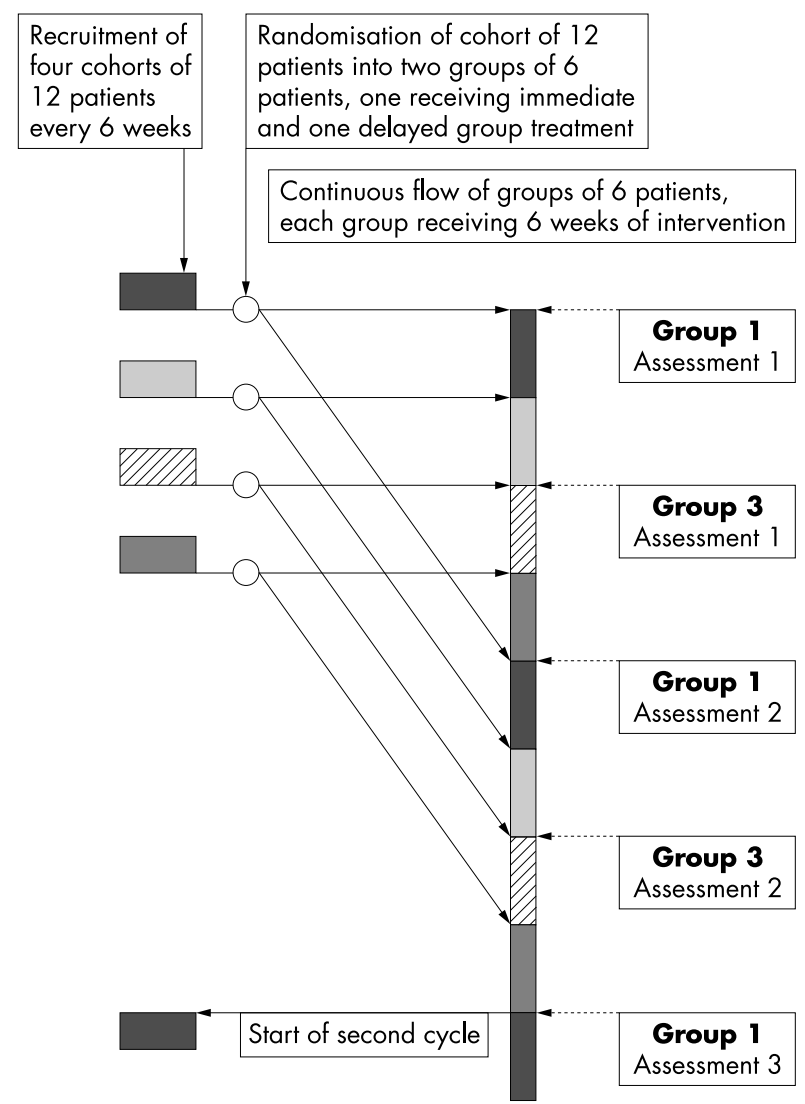

Figure 1 Design of study; cycle 1 of three; flow of first 48 patients over 48 weeks

was undertaken ${ }^{20}$ using the SPSS general linear model procedure. ${ }^{21}$ The effect of the intervention was tested by the statistical interaction between treatment group and time. A significant interaction would indicate that patients who had received the intervention had fared differently from those who had not. A second analysis using a similar procedure compared data from all patients before rehabilitation and four months after.

To be included, the following criteria had to be fulfilled: the patients had to have Parkinson's disease diagnosed clinically by a consultant neurologist (PT) with a special interest in the disease; they had to give their consent; there should be no major cognitive losses (defined as scoring $7 / 10$ or more on the abbreviated mental test ${ }^{22}$ ); and they had to be able to attend the day hospital using either their own or hospital transport. After agreeing to participate they were accumulated into cohorts of 12 patients and then randomised using a computer generated block randomisation procedure giving two groups of six. This was undertaken at an independent institution, and the rehabilitation programme organiser was told the group for each registered patient.

The assessments used were a Parkinson's disease disability questionnaire ${ }^{23}$; the Parkinson's disease questionnaire (PDQ$\left.39^{24}\right)$; the short form 36 item health survey $(\mathrm{SF}-36)^{25}$; the Euroqol-5d (an index of health related quality of life $)^{26}$; the stand-walk-sit test, ${ }^{27}$ reported as seconds to complete test; the nine hole peg test (NHPT) of manual dexterity, reported as seconds to place all nine pegs ${ }^{28}$; the hospital anxiety and depression scale $\left(\mathrm{HADs}^{29}\right)$; and selected items concerning speech from the unified Parkinson's disease rating scale (UPDRS). ${ }^{30}$. Carers were assessed using the carer strain index ${ }^{31}$ and the Euroqol-5d.

The assessments were undertaken in the day hospital by an independent assessor who was not involved in the treatment

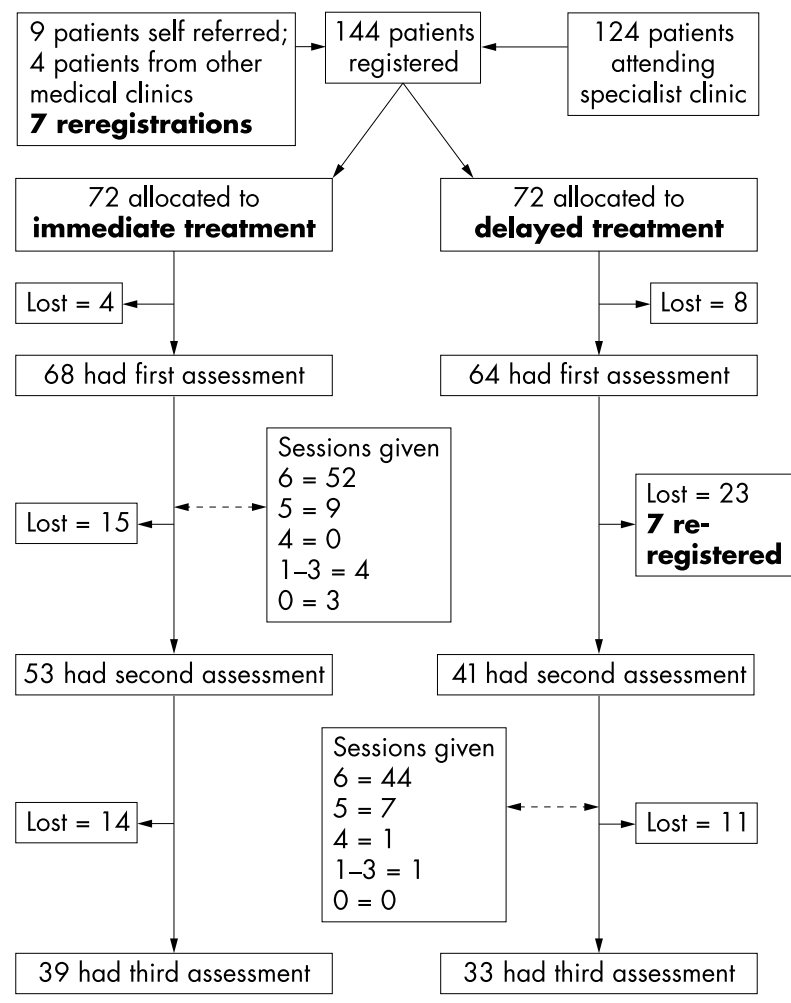

Figure 2 Patient flow through the study.

programme and who was not informed of the patient's group. The same assessments were used at time zero (after randomisation before any treatment), at 24 weeks (after one group had received treatment but before the other group started treatment), and at 48 weeks.

The intervention comprised a multidisciplinary rehabilitation programme. The patient attended for whole days, coming in once a week for six consecutive weeks. In the first week the patient was assessed and an individualised programme of one to one treatment was planned, to run over the next five weeks from a specialist team including a Parkinson's disease specialist nurse, a physiotherapist, a speech and language therapist, and an occupational therapist. Each week the patient then received two hours of individual treatment in the morning, followed by group activities (for example, talks from experts and relaxation) in the afternoon. All patients were assessed by a social services care manager. The content of the programme is available from the authors. After their last attendance each patient was reassessed using a small battery of measures reported elsewhere. ${ }^{19}$

\section{RESULTS}

In all, 137 separate patients were included, but there were 144 registrations because seven patients in the delayed treatment group withdrew before treatment but then requested re-entry; these were re-entered (and re-randomised) with a new number. Of the 144 registrations, 124 (86\%) were from a specialist Parkinson's disease neurology clinic, nine from self referral, four from geriatric clinics, and seven were reregistrations. The flow the 144 registered patients is shown in fig 2. The patients who withdrew and re-entered have only been included once in any analysis.

Difficulties with transport and intercurrent illness led to some patients missing one or more assessments or withdrawing from the study. Consequently only 71 patients had all three assessments, 94 had both a first and a second assessment, and 86 had assessments both before and after their allocated treatment spell. 
Table 1 Comparison of early and late groups with full data from first and second assessments $(n=94)$

\begin{tabular}{|c|c|c|c|c|c|}
\hline & \multicolumn{2}{|l|}{ Baseline } & \multicolumn{2}{|l|}{24 weeks } & \multirow[b]{2}{*}{ Significance* } \\
\hline & Early & Late & Early & Late & \\
\hline \multicolumn{6}{|l|}{ Patients } \\
\hline $\mathrm{n}$ & 53 & 41 & 53 & 41 & \\
\hline Male:female (n) & $30: 23$ & $26: 15$ & & & \\
\hline Age (years) & $71.3(8.6)$ & $70.4(7.6)$ & & & \\
\hline $\begin{array}{l}\text { PD disability questionnaire: } 25 \text { (good) to } \\
125\end{array}$ & $48.9(14.4)$ & $50.3(18.0)$ & $53.4(17.4)$ & $55.3(19.5)$ & 0.558 \\
\hline PDQ-39: 0 (good) to 100 & $26.1(11.3)$ & $27.6(12.2)$ & $26.7(13.7)$ & $26.2(13.2)$ & 0.439 \\
\hline $\begin{array}{l}\text { SF-36 physical component summary: } 0 \\
\text { (bad) to } 100\end{array}$ & $29.8(10.8)$ & $29.7(9.7)$ & $28.8(10.9)$ & $28.1(11.8)$ & 0.602 \\
\hline $\begin{array}{l}\text { SF-36 mental component summary: } 0 \text { (bad) } \\
\text { to } 100\end{array}$ & $50.6(8.8)$ & $48.0(10.4)$ & $49.8(10.7)$ & $51.2(9.0)$ & $0.037^{\circ}$ \\
\hline $\begin{array}{l}\text { SF-36 mental health subscale: } 0 \text { (bad) to } \\
100\end{array}$ & $71.1(15.2)$ & $67.6(19.2)$ & $67.9(18.3)$ & 72.5 (13.5) & $0.019^{b}$ \\
\hline $\begin{array}{l}\text { SF-36 general health subscale: } 0 \text { (bad) to } \\
100\end{array}$ & $50.4(21.5)$ & $43.8(17.4)$ & 42.7 (18.7) & $48.0(17.6)$ & $0.002^{c}$ \\
\hline Stand-walk-sit time (s) & $20.1(8.7), n=49$ & $21.5(8.0), n=39$ & $19.4(6.9), n=49$ & $23.2(10.3)^{d}, n=39$ & 0.093 \\
\hline Nine hole peg test (s) & $23.9(31.2), n=51$ & $20.2(7.4), n=41$ & $\begin{array}{l}20.4(14.8) \\
n=52\end{array}$ & $20.0(8.1), n=40$ & 0.273 \\
\hline Euroqol scale: -0.59 (bad) to 1.00 & $0.73(0.20)$ & $0.74(0.18)$ & $0.66(0.22)$ & $0.67(0.27)$ & 0.951 \\
\hline Euroqol VAS: 0 (bad) to 100 & 72.7 (17.4) & 71.4 (14.7) & $68.2(18.6)$ & $68.7(15.9)$ & 0.633 \\
\hline UPDRS, speech: 0 (good) to 4 & $1.40(0.97)$ & $1.68(0.93)$ & $1.60(0.97)$ & $1.61(0.97)$ & 0.129 \\
\hline UPDRS, salivation: 0 (good) to 4 & $1.13(1.11)$ & $1.24(1.04)$ & $1.21(1.03)$ & $1.34(1.17)$ & 0.922 \\
\hline UPDRS, swallowing: 0 (good) to 4 & $0.89(1.05)$ & 0.85 (1.09) & $1.15(1.10)$ & $1.10(1.07)$ & 0.923 \\
\hline UPDRS, writing: 0 (good) to 4 & $2.17(1.14)$ & $2.27(1.16)$ & $2.30(1.15)$ & $2.46(1.05)$ & 0.747 \\
\hline HAD, anxiety: 0 (good) to 21 & $6.1(3.5)$ & $6.2(3.4)$ & $6.1(3.4)$ & $5.8(3.6)$ & 0.472 \\
\hline HAD, depression: 0 (good) to 21 & $5.6(3.9)$ & $5.0(3.6)$ & $5.2(3.3)$ & $4.9(3.2)$ & 0.625 \\
\hline \multicolumn{6}{|l|}{ Carers $(n=68)$} \\
\hline Carer strain index: 0 (no strain) to 13 & $3.0(2.7), n=40$ & $3.6(3.4), n=28$ & $3.7(3.0), n=39$ & $3.3(3.0), n=28$ & $0.086^{\mathrm{e}}$ \\
\hline Euroqol scale: -0.59 (bad) to 1 & $0.86(0.21), n=40$ & $0.83(0.33), n=27$ & $\begin{array}{l}0.82(0.20) \\
n=39\end{array}$ & $0.81(0.18), n=29$ & 0.592 \\
\hline Euroqol VAS: 0 (bad) to 100 & $78.4(17.1), n=40$ & $79.0(14.5), n=27$ & $\begin{array}{l}77.8(19.8) \\
n=39\end{array}$ & $80.8(14.5), n=29$ & 0.996 \\
\hline \multicolumn{6}{|c|}{$\begin{array}{l}\text { Unless otherwise stated, values are mean (SD). } \\
\text { * Statistical significance of difference in change scores after use of general linear model analysis of variance. } \\
\text { 'Treated group had deterioration in emotional distress and controls improved at } 24 \text { weeks relative to baseline. } \\
\text { bTreated group had deterioration in mental health and controls improved at } 24 \text { weeks relative to baseline. } \\
\text { 'Treated group had deterioration in general health and controls improved at } 24 \text { weeks relative to baseline. } \\
\text { dTreated group significantly faster, } p=0.044 \text { on direct comparison; } p=0.093 \text { relative to baseline. } \\
\text { 'Carers of treated group had increased strain and controls less strain at } 24 \text { weeks relative to baseline. } \\
\text { HAD, hospital anxiety and depression scale; PD, Parkinson's disease; PDQ-39, Parkinson's disease questionnaire; SF-36, short form 36; VAS, UPDRS, } \\
\text { unified Parkinson's disease rating scale; visual analogue scale. }\end{array}$} \\
\hline
\end{tabular}

The baseline characteristics of the 94 patients and 68 carers entered into the analysis are shown in table 1 . The two groups were similar on all variables, with no statistically significant differences. The results on the same measures at the six month crossover point are also shown in table 1. At this point the second group was about to start treatment. There was only one significant difference between the two groups-those patients in the treated group who were able to walk on both occasions were faster on the stand-walk-sit test $(\mathrm{p}=0.044)$.

The results of general linear modelling analysis, ${ }^{20}{ }^{21}$ allowing for the initial patient state and the patient cohort, are shown in column 5 of table 1. Significant differences were recorded for SF-36 mental component summary scores and in the SF-36 general health and mental health subscales: the treated group had deteriorated while the control group had improved at the crossover point. Similarly, the carers of treated patients showed more strain, while the carers of patients about to start rehabilitation showed less strain. Finally, patients in the treated group showed a slight increase in speed in the standwalk-sit test, while the control group showed some deterioration.

A related measures $t$ test was used to compare the data from before treatment with the data from six months after the treatment started in the 86 patients who had full pre- and postintervention data (table 2 ). This showed that, despite treatment, patients deteriorated significantly on some measures and showed no improvement, which is consistent with the fact that Parkinson's disease is a progressive disorder. A statistically significant deterioration was recorded in four measures: the Parkinson's disease disability questionnaire, ${ }^{23}$ the SF-36 physical component summary, the SF-36 general health subscale, and the Euroqol scale value. The carers also showed more strain on the carer strain index.

Comparison of the 94 patients included in the primary analysis with the remaining 43 patients (data not shown) showed that the patients who did not complete the rehabilitation programme and research protocol were more disabled and older at baseline.

\section{DISCUSSION}

The main findings were a consistent worsening in all patient measures, reaching statistical significance in their emotional state and in carer stress over six months. This decline was largely unaffected by rehabilitation, although there may have been a minor, equivocal benefit on the mobility of walking patients. This is in contrast to the data from the same patients recorded immediately after intervention, which did show beneficial effects. ${ }^{19}$ The study suffered from considerable loss of patients but nonetheless it is one of the largest randomised studies of non-pharmacological treatments for patients with Parkinson's disease, and it shows that such trials are feasible.

One major weakness in the study is the loss of data from the oldest and most disabled patients. However, the assessor was independent of the treatment team, and was not aware of a patient's group when assessing a patient. It seems unlikely that the loss of data has biased the results, and we believe that 
Table 2 Comparison of 86 patients before treatment and 24 weeks later

\begin{tabular}{|c|c|c|c|}
\hline Group & Before & After & Significance* \\
\hline \multicolumn{4}{|l|}{ Patients $(n=86)$} \\
\hline Male:female (n) & $50: 36$ & $50: 36$ & \\
\hline Age (years) & $71.3(8.6)$ & & \\
\hline PD disability questionnaire & $51.7(17.6)$ & 54.8 (18.9) & $0.031^{a}$ \\
\hline PDQ-39 & $25.5(10.7)$ & $26.0(12.7)$ & 0.687 \\
\hline SF-36 physical component summary & $29.5(11.1)$ & $27.28(10.9)$ & $0.046^{\circ}$ \\
\hline SF-36 mental component summary & $51.0(8.4)$ & $50.5(10.3)$ & 0.655 \\
\hline SF-36 mental health subscale & $71.5(13.5)$ & $70.3(17.2)$ & 0.474 \\
\hline SF-36 general health subscale & $50.3(21.0)$ & $38.65(19.5)$ & $<0.001^{a}$ \\
\hline Euroqol scale & $0.72(0.22)$ & $0.66(0.21)$ & $0.026^{a}$ \\
\hline Euroqol VAS & $71.9(16.4)$ & $68.2(19.4)$ & 0.110 \\
\hline Stand-walk-sit test (s) & $22.9(18.2), n=82$ & $22.2(13.5), n=83$ & 0.752 \\
\hline Nine hole peg test seconds & $22.4(24.8), n=83$ & 20.7 (13.0), $n=83$ & 0.313 \\
\hline UPRS, speech & $1.42(0.96)$ & $1.51(0.95)$ & 0.380 \\
\hline UPRS, salivation & $1.27(1.22)$ & $1.36(1.10)$ & 0.369 \\
\hline UPRS, swallowing & $0.91(1.05)$ & 0.97 (1.05) & 0.607 \\
\hline UPRS, writing & $2.29(1.16)$ & $2.38(1.12)$ & 0.729 \\
\hline$H A D$, anxiety & $6.0(3.4)$ & $5.8(3.21)$ & 0.729 \\
\hline HAD, depression & $5.2(3.6)$ & $5.0(3.2)$ & 0.638 \\
\hline \multicolumn{4}{|l|}{ Carers $(n=63)$} \\
\hline Carer strain index & $3.1(2.7), n=61$ & $3.8(3.2), n=62$ & $0.045^{\circ}$ \\
\hline Euroqol scale & $0.82(0.22)$ & $0.79(0.24)$ & 0.235 \\
\hline Euroqol VAS & $78.0(16.6)$ & 77.5 (19.5) & 0.873 \\
\hline \multicolumn{4}{|c|}{$\begin{array}{l}\text { Unless otherwise stated, values are mean (SD). } \\
\text { * } p \text { value of paired } t \text { test. } \\
\text { aPatients or carers worse at } 24 \text { weeks, after treatment, on these measures. } \\
\text { HAD, hospital anxiety and depression scale; PD, Parkinson's disease; PDQ-39, Parkinson's disease } \\
\text { questionnaire; SF-36, short form 36; UPDRS, unified Parkinson's disease rating scale; VAS, visual analogue } \\
\text { scale. }\end{array}$} \\
\hline
\end{tabular}

the results are secure. Nevertheless, it will have reduced the power of the study, and it is possible that some significant effects have been missed. Moreover, the crossover design may have led to some bias against treatment. At the crossover point the patients in the treated group were not only 18 weeks away from treatment, but they were also aware that no more treatment would be available. Given that they had experienced benefit themselves after treatment, ${ }^{19}$ they may have been feeling depressed. In addition it is possible that attendance and the educational package may have increased their awareness of future deterioration, causing some distress. In contrast the control group patients were about to start treatment, which may have improved their mood. This might be the explanation for the consistent changes in mood and carer strain found.

Our study gives useful information on the measurement of disability in trials investigating Parkinson's disease. The assessments used were all practical, and some measures did detect the expected deterioration over 24 weeks, particularly the Parkinson's disease disability measure, ${ }^{23}$ which has also been found to be sensitive to rehabilitation input in another trial of rehabilitation in Parkinson's disease. ${ }^{32}$ The stand-walksit test, the carer strain index, the SF-36, and the Euroqol also seemed sensitive to change, whereas the PDQ-39 did not. This study not only provides data that will allow others to make more accurate power calculations but also suggests that these measures (or an equivalent timed measure of mobility) might be the best measures to use.

One notable finding of this study is the consistent decline in almost all measures over the six month period. This was of similar size in both the treated and untreated patients, and mirrors the gradual decline also found in stroke patients later after stroke. ${ }^{33}$

In contrast to the uniform decline in function, the minor differences in change of function detected are difficult to evaluate and may simply arise through chance. However, the intervention may have improved mobility and this is worth investigating further because a similar small input was found to improve mobility late after stroke. ${ }^{33}$ The effect on the patient's emotional state and perception of health and carer strain is also difficult to evaluate because, as stated above, it is possible that at the crossover point the control group patients were feeling better precisely because they were about to start the programme, whereas the patients who had already had the intervention were depressed because no further input was going to happen.

Why was little evidence of benefit found? The fact that the patients were largely recruited from a specialist neurological clinic might mean that they were already well managed, and had received other professional support, and that there was only a limited scope for further improvement. Second, it might be argued that six days of rehabilitation totalling about 10 hours of face to face treatment and 10 hours of group therapy was too little to expect to find effects 18 weeks after stopping it. Third, the team did not include a clinical psychologist or a doctor, but the specialist nurse did refer patients back to the neurologist if necessary. Fourth, the immediate assessment of patients after the programme showed significant improvement across a range of measures and high participant satisfaction $^{19}$ and therefore it is possible that patients need repeated input to sustain early improvement in the face of a progressive deterioration. Fifth, the measures may either have failed to assess domains where major benefits were occurring, or may have been insensitive to clinically significant change. Our finding of a decline in most measures over six months is consistent with the known progress of the disease and suggests that the measures were adequately sensitive to change even though some measures such as the UPDRS subscales were weak. Our measures cover all activity domains that seem to be relevant. Last, the study may have been too small to detect a benefit.

\section{Conclusions}

Several conclusions can be drawn. First, the design and measures used were practical, and consequently we have shown that it is possible to undertake research into multiprofessional rehabilitation in patients with Parkinson's disease in a district general hospital. Second, we have given an estimate both of the variance in outcome data and of the likely 
loss of patients in such studies. Third, this study neither supports individual rehabilitation combined with group therapy nor does it show it to be ineffective. The particular circumstances-with patients coming from a specialist clinic and the lack of follow up rehabilitation-may have made it difficult to show sustained benefit. Fourth, we believe that future studies should investigate from a clinical and economic perspective both the content of rehabilitation, especially the involvement of clinical psychologists, and also varying patterns of delivery (for example, regular follow up and a more local, more prolonged, but less frequent programme of rehabilitation). Last, future studies could reduce the range of assessments used to a subset of those used in this study.

\section{ACKNOWLEDGEMENTS}

The study was funded by Parkinson's Disease Society of UK, RSCH NHS Trust, SHB NHS Trust, Guildford Rotary, Guildford Inner Wheel, and many individual donors. We especially thank Chris Marney and Joan Morrison-Lyden for all their help in planning and running the study. Treatment was given by: Jane Allan (physiotherapist), Jane Farquharson (occupational therapist), and Sarah Morrison and her speech and language therapy colleagues. We thank Dr V Seth for recruiting some patients, and the day hospital and ambulance service for their cooperation. Finally we thank the patients and carers for helping us so willingly.

\section{Authors' affiliations}

D T Wade, Oxford Centre for Enablement, Windmill Road, Oxford, UK H Cage, Department of Economics, University of Surrey, Guildford, UK C Owen, Thomas Coram Research Unit, Institute of Education, London WCl, UK

P Trend, Department of Neurology, Royal County Surrey Hospital, Guildford

C Grossmith, Social Services Dept, Royal County Surrey Hospital J Kaye, Specialist Nurse, Surrey Hampshire Borders NHS Trust, Guildford

Competing interests: DTW runs a neurological rehabilitation service; JK is a specialist Parkinson's disease nurse who is involved in treating patients; otherwise none.

\section{REFERENCES}

1 Mutch WJ, Dingwall-Fordyce I, Downie AW, et al. Parkinson's disease in a Scottish city. BM 1986;292:534-6.

2 Wade DT, Langton-Hewer R. Epidemiology of some neurological diseases - with special reference to work load on the NHS. Int Rehabil Med 1986:8:129-37.

3 Fletcher N. Movement disorders. In: Brain's diseases of the nervous system. Ed: Donaghy M, 11 th ed. Oxford: Oxford University Press, 2001:1030-6.

4 Nicholson T, Milne R. Pallidotomy, thalamotomy and deep brain stimulation for severe Parkinson's disease. Southampton: Development and Evaluation Committee report. Development and evaluation, 1999: 1-63.

5 Pacchetti C, Mancini F, Aglieri R, et al. Active music therapy in Parkinson's disease: an integrative method for motor and emotional rehabilitation. Psychosom Med 2000:62:386-93.

6 Marchese R, Diverio M, Zucchi F, et al. The role of sensory cues in the rehabilitation of parkinsonian patients: a comparison of two physical therapy protocols. Move Disord 2000;15:879-83.

7 Miyai I, Fujimoto Y, Ueda Y, et al. Treadmill training with body weight support: its effect on Parkinson's disease. Arch Phys Med Rehabil 2000;81:849-52.
8 Comella CL, Stebbins GT, Brown-Toms N, et al. Physical therapy and Parkinson's disease: a controlled clinical trial. Neurology 1995; $44: 376-8$

9 Schrag A, Jahanshahi M, Quinn N. What contributes to quality of life in patients with Parkinson's disease? J Neurol Neurosurg Psychiatry 2000;69:308-12

10 de Goede CJ, Keus SH, Kwakkel G, et al. The effects of physical therapy in Parkinson's disease: a research synthesis. Arch Phys Med Rehabil 2001:82:509-15.

11 Deane KHO, Jones D, Playford ED, et al. Physiotherapy versus placebo or no intervention in Parkinson's disease (Cochrane review). In: The Cochrane library, issue 2. Oxford: Update Software, 2002.

12 Deane KHO, Whurr R, Playford ED, et al. Speech and language therapy versus placebo or no intervention for dysarthria in Parkinson's disease (Cochrane review). In: The Cochrane library, issue 2. Oxford: Update Software, 2002

13 Gage H The effectiveness of rehabilitation in Parkinson's disease: a review of available evidence. Clin Rehabil (in press).

14 Stroke Unit Trialist's Collaboration. Collaborative systematic review of the randomised trial of organised inpatient (stroke unit) care after stroke. BM 1997;314:1151-9

15 Freeman JA, Langdon DW, Hobart JC, et al. The impact of inpatient rehabilitation on progressive multiple sclerosis. Ann Neurol 1997:42:236-44.

16 Forster A, Young J, Langhorne P, for the Day Hospital Group. Medical day hospital care for the elderly versus alternative forms of care (Cochrane review). In: The Cochrane library, issue 4. Oxford: Update software, 2001.

17 Gerard K. An appraisal of the cost-effectiveness of alternative day hospital settings for frail elderly people. Age Ageing 1988;17:311-18.

18 Gauthier L, Dalziel S, Gauthier S. The benefits of group occupational therapy for patients with Parkinson's disease. Am J Occup Ther 1987:41:360-5.

19 Trend P, Gage H, Kaye J, et al. Short-term effectiveness of co-ordinated multi-disciplinary rehabilitation for people with Parkinson's disease and their carers. Clin Rehabil 2002;16:717-725.

20 Bock RD. Multivariate statistical methods in behavioural research. New York: McGraw-Hill, 1975: section 7.2

21 SPSS. SPSS advanced models 10.0. Chicago: Statistical Package for Social Sciences, 1999: chapter 2

22 Hodkinson HM. Evaluation of a mental test score for assessment of mental impairment in the elderly. Age Ageing 1972;1:233-8.

23 Brown RG, MacCarthy B, Jahanshahi $M$, et al. Accuracy of self-reported disability in patients with Parkinsonism. Arch Neurol 1989;46:955-9.

24 Jenkinson C, Fitzpatrick R, Peto V, et al. The Parkinson's disease questionnaire (PDQ-39): development and validation of a Parkinson's disease summary index score. Age Ageing 1997:26:353-7.

25 Ware JE, Sherbourne CD. The MOS 36-item short-form health survey (SF-36). I. Conceptual framework and item selection. Med Care 1992;30:473-83

26 Kind $\mathbf{P}$. The Eurogol instrument: an index of health-related quality of life. In: Spiker B, ed. Quality of life and pharmacoeconomics in clinical trials, 2nd ed. Philadelphia: Lippincott-Raven, 1996:191-201.

27 O'Sullivan JD, Said CM, Dillon LC, et al. Gait analysis in patients with Parkinson's disease and motor fluctuations: influence of levodopa and comparison with other measures of motor function. Move Disord 1998;13:900-6.

28 Heller A, Wade DT, Wood VA, et al. Arm function after stroke: measurement and recovery over the first three months. J Neurol Neurosurg Psychiatry 1987;50:714-19.

29 Zigmond AS, Snaith RP. The hospital anxiety and depression scale. Acta Psychiatr Scand 1983:67:361-70

30 van Hilten JJ, van der Zwan $A D$, Zwinderman $A H$, et al. Rating impairment and disability in Parkinson's disease: evaluation of the unified Parkinson's disease rating scale. Move Disord 1994:9:84-8.

31 Robinson BC. Validation of a caregiver strain index. J Gerontol 1983;38:344-8.

32 Stallibrass C, Sissons P, Chalmers C. Randomised controlled trial of the Alexander technique for idiopathic Parkinson's disease. Clin Rehabil 2002; 16:695-708.

33 Wade DT, Collen FM, Robb GF, et al. Physiotherapy intervention late after stroke and mobility. BM 1992;304:609-13. 